\title{
Nonverbal Communication in College English Classroom Teaching
}

\author{
Liangguang Huang \\ English Department, Zhenjiang Watercraft College of PLA, Zhenjiang 212000, China \\ Email: Blackhawk1975@126.com
}

\begin{abstract}
Human communication can be divided into two categories: verbal communication and nonverbal communication, where verbal means is commonly considered to be the most important, efficient, powerful means of communication. Over decades, much attention has been given to the research on verbal communication, while a very important fact was neglected: in face-to-face communication, the use of nonverbal communication is more common than that of verbal communication, and it is an essential part of human communication, which plays a significant role. Ignorance of nonverbal messages will result in incompleteness. In the past two decades, college English teaching has made great achievements. Yet problems still prevail. Daily classroom teaching is still inefficient although a lot of time and money has been spent on. One of the reasons for that is that nonverbal communication is neglected in daily classroom teaching. Teachers' nonverbal communication plays an important role in college English classroom teaching. Many studies find that teachers should learn to use nonverbal communication to improve the quality of classroom teaching. A famous scholar Cooper holds that if the teacher knows how to use nonverbal communication more efficiently. The relationship between the teacher and students will be improved, and the recognitive ability and learning efficiency of the students will also be developed.
\end{abstract}

Index Terms - college English, classroom teaching, nonverbal communication

\section{INTRODUCTION}

Communication is the basis of all human contact, which is central to human life. People communicate in many different ways. One of the most important ways, of course, is through language. Moreover, when language is written it can be completely isolated from the context in which it occurs; it can be treated as if it were an independent and self-contained process. We have been so successful in using, describing and analyzing this special kind of communication that we sometimes act as if language were the only kind of communication that can occur between people.

However, effective human communication falls into two types: verbal communication and nonverbal communication. For a long time, only the former one occurred to us immediately when we discuss human communication, while the latter was neglected to a large extent. In fact, nonverbal communication plays a very important role in human social behavior. Its importance has been fully accounted for by communication theorists. As Henry David Thoreau has ever said that in human intercourse the tragedy begins not when there is misunderstanding about words, but when silence is not understood.

Bi Jiwan states, "Western scholars believe that the role of nonverbal communication in classroom teaching is greater than that of formal teaching for students' learning. Research has indicated that teachers are required to learn to use nonverbal communication to improve classroom teaching." (1993:153) Classroom teaching and learning activity, especially college English classroom teaching and learning is a kind of communication between teachers and students. In this course both teachers and students use nonverbal and verbal means to communicate consciously or unconsciously. Teachers, especially college English teachers, as a bridge to international communication and information-sender, should be strongly aware of the importance of nonverbal communication, because nonverbal behaviors convey many messages in classroom, and become invaluable for teachers in getting the message across to class and understanding the messages of interest or messages of confrontation that students are sending. Their positive nonverbal cues can also influence the teacher's state of mind and the classroom atmosphere, and further improve the effect of classroom instruction. Generally speaking, the students' involvement and interest in the subject can be detected from their relaxed faces and smiles. So we can say, nonverbal communication between teachers and students plays an important role in college English classroom teaching.

\section{NONVERBAL COMMUNICATION}

\section{A. The Definition of Nonverbal Communication}

Before we try to explore nonverbal communication and its role in college English classroom teaching, we need to understand what nonverbal communication is. As for the definition of nonverbal communication, there are a variety of versions given by different people, some of which are very simple, while the others are more specific. Mask Knapp 
(1980:18) states, "Generally, when people refer to nonverbal communication, they are talking about the signals to which meaning will be attributed - not the process of attributing meaning ..." Here we shall therefore select one definition that is consistent with current thinking in the field. Samovar and Porter (2000) propose that nonverbal communication involves all those nonverbal stimuli in a communication setting that are generated by both the source and his or her use of the environment and that have potential message value for the source of receiver.

We can come to the conclusion that the purpose of giving such a somewhat lengthy definition is to offer a definition that would not only mark the boundaries of nonverbal communication, but also reflect how the process actually works. This definition not only includes unintentional but intentional behaviors in the total communication event.

\section{B. The Classification of Nonverbal Communication}

As different linguists describe nonverbal communication in different dimension, there are many ways of categorizing nonverbal communication, among which the earliest is the one raised by Ruesch and Kees. They suggested there be three types of nonverbal behaviors based on the foundational components of nonverbal communication: sign language, action language, and object language. In Michael Argyle's book (1984) Bodily Communication, nonverbal communication is identical to body language, including facial expressions, gaze, gestures and bodily movements, postures, bodily contact, spatial behavior, clothes, physique and other aspects of appearance and nonverbal vocalizations.

In China, He Daokun (1988) proposed nonverbal communication concern the following categories as Time language, space language, body language, voice modulation and environment. In Bi Jiwan's (1999) opinion, nonverbal communication can be divided into the four classes: 1. Body language, including basic posture, gesture, basic manners and movements of any part of the body. 2. Paralanguage, referring to these elements such as pitch, speed, volume, tone, rhyme, silence and pause. 3. Object language, consisting of smell, complexion, clothing, cosmetics, furniture, etc. 4. Environment language, including time, space, colors, city planning and any human effect on nature. And according to him, the former two can be called "Nonverbal Behavior" and the latter two "Nonverbal Means".

\section{The Significance of Nonverbal Communication}

Leger Brosnahan (1991) says that half of the information in the communication is carried on the nonverbal band. Samovar (1981) positively expresses his view that most authorities believe that in a normal two-person conversation, the verbal components carry less than $35 \%$ of the total social meaning of the situation and that more than $65 \%$ is carried on the nonverbal band. Although we don't know whether these figures are accurate or not, at least they informed of us the significant roles that nonverbal communication plays in our daily interactions.

With the rapid development of Media, the wide spread of knowledge, and the frequent communication among people, the significance of nonverbal communication has grown to such an extent that it is how we say the words counts, instead of what we say. "Eyes are more accurate witnesses than ears." As Heraclitus remarked over two thousand years ago, we can infer that because nonverbal actions are not easily controlled consciously, they can precisely betray one's true feeling without distortion and deception. It is difficult to control a blushing face when we are embarrassed or a clenched jaw when we are angry. In fact, research indicates that we will believe nonverbal messages instead of verbal ones when the two contradict each other.

Nonverbal communication has value in human interaction because it is usually responsible for first impressions. Our first judgments are often based on the color of a person's skin or the manner in which he or she is dressed, which usually influences the perception of everything else that follows. Nonverbal communication is important to the study of intercultural communication because a great deal of nonverbal behavior speaks a universal language. Behaviors such as smiling, frowning, laughing and crying tend to have similar meanings, whether in China, America or any countries in Europe.

Verbal communication and nonverbal communication are integrated in human communication. The latter isn't the rest of human interaction with the absence of verbal communication, nor is the additional complementary one, but an indispensable action which plays a functional role in human communication. On one hand, a single verbal communication without any nonverbal communication can't be easily understood by people; on the other, it is companied by words that nonverbal communication can express explicit meanings, and there is no isolated nonverbal communication. It is the cooperation of verbal communication and nonverbal communication that forms the whole process of effective human communication. That is to say, we might see better that verbal message are more appropriate for some exchanges and nonverbal messages for others, and that both have their natural and complementary roles to play in human society.

\section{The Relationship between Nonverbal Communication and College English Classroom Teaching}

Although nonverbal communication plays a central role in human behavior, it remains for from being well understood. Earlier approaches to foreign language teaching and learning were basically oriented to the development of grammatical accuracy rather than communicative skills. College English teachers used to focus on English grammar and vocabulary, ignorant of the practical application of nonverbal communication so that the students feel the teachers' lectures are boring and they are frequently absent on purpose. With the advancement of linguistic science and teaching methodology research, the idea of developing learners' ability to use the target language for successful communication 
has become more and more popular. Experts and language teachers have become more and more aware of the effects of nonverbal communication on foreign language teaching. More understandings will be made if nonverbal communication companies the language. If the teacher's nonverbal communication is vivid and alive, it will be helpful for the students' understanding and command of knowledge in the classroom and it's also much easier for students to memorize. All these researches indicate that the teacher should be in high spirits and active.

Many western scholars hold that the nonverbal communication in the class is much more important in the students' study than in the regular teaching itself. If the teachers know well how to use nonverbal actions more effectively, the relationship between the teachers and the students will be improved, the students' cognitive ability and study effect alike. In 2007, in order to adapt to the new developing situation of national higher education, deepening the educational reform, upgrading the teaching quality and fitting in with the needs of the society, the Ministry of Education of China released the new College English Course Teaching and Learning Requirements. It indicates that English knowledge, applied skill, learning strategies are included in the objective of college English teaching, while cross-cultural communication includes the competence of verbal communication and that of nonverbal communication. To be exact, it is composed of three parts: written communication ability, oral communication ability and nonverbal communication ability. We can understand that nonverbal communication is an integrated part of English classroom teaching. Therefore college English teachers should fully realize the role played by nonverbal behaviors, let alone nonverbal behaviors performed by themselves, for the teachers' appropriate nonverbal behaviors not only improve the relationship between the teachers and the students, but also set up a good image for the students. For a vivid smile, an encouraging gesture, or a gentle expression in teachers' eyes can be effective tools for the improvement of the relation between teachers and students, which can also consequently improve classroom teaching effect.

\section{The Practical ApPlication of NonVerbal Communication In Classroom Teaching}

\section{A. Kinesics}

The study of how movement communicates is called kinesics, or body language. As the most frequent use of nonverbal cues in class, kinesics can lead to the level of effectiveness of teaching directly. Teachers' smile, nod and pat of students' shoulders can indicate praise, while frown, head-shaking and confusing look can mean "no", and students' body language can convey their affection to the teacher and their attitudes toward the courses that they learn and toward school's rules. Here we would like to look into some of the more significant movements of kinesics from these five parts in great details. They are facial expressions, eye contact, gesture, posture as well as touch of teachers.

1. Facial Expression

Facial expression is a look on a person's face, and facial cues are the first information that we give to or receive from others. People get information about the type of the person, personality traits from face. Facial expression between teachers and students is one of the most important types of nonverbal signals in the classroom. In English class, the lively facial expressions can promote a supportive and non-threatening classroom atmosphere, which aids students' positive attitudes and corresponding achievement. When the teacher raises a question in English, an expectant expression he shows can encourage students to think carefully and answer actively. Sometimes an unconscious frown can make sensitive student correct his answer immediately. It is much better than just saying "No" or "Wrong", which can protect the students' proper pride. In addition, a teacher should often smile in class, a smiling teacher is thought to convey warmth and encouragement in all cultures, and will be perceived as more likable, friendly, warm and approachable.

\section{Eye Contact}

Eye contact is another important aspect of kinesics. We communicate a great deal through our eyes, perhaps more than through any other part of the body. As the saying goes, "The eyes are the window of the soul." The use of eye contact as an avenue of communication is relatively obvious. People are remarkably accurate in judging the direction of another person's gaze; psychologists have done experiments that have measured just how accurate such judgments are. In college English classroom, from an observation of where a student is looking the teacher can infer what the student is looking at, and from knowing what he is looking at the teacher can guess what he is interested in, and from what he is interested in and the general situation the teacher can usually make a fairly good guess about what he is going to do. Thus eye movements can be a rich and important channel of nonverbal communication.

There are two kinds of eye contact that the teacher often uses in class. One is looking around, which plays a very useful role in classroom teaching. On the one hand, it can be used to get the students' attention, to encourage students to think carefully, and to find the students who get or nearly get the answer so as to put questions to. On the other, it can be used as a means in classroom control. Another kind of eye contact is looking attentively or gaze. When the teacher criticizes the student's bad behavior, his eyesight should put on the triangle part of the students' face. By doing so, the teacher will be impressed as serious, careful and honest.

If a teacher looks at every student in the classroom or avoids looking at students, he conveys the attitude of intimacy, aloofness, concern, depression or indifference. Teachers often watch their students carefully for the sign of fatigue, boredom, confusion, or enthusiasm, for all these things will be communicated to the teachers through their eyes during the teachers' presentation.

English class may be a little more special than other classes, because English class requests students to talk more 
with teachers, especially, in English. Many students comment that they feel the most nervous in English class. So when the teacher ask someone to answer questions in English class, the messages expressed by his eyes should be more encouraging, more soft, may be just "as warm as spring". Then the students may feel more relaxed, get more self-confidence and practice their oral English more freely and willingly. So as time going on, a warm atmosphere can come into being and the level of students' spoken English can be improved obviously.

3. Gestures

Being the most common form of nonverbal behaviors in daily life, we need to understand the gestures of people. A gesture is an expressive motion or action, usually made with the hands and arms, but also with the head or even the while body. Gestures can occur with or without speech. Some gestures are spontaneous, some are highly ritualized and have very special meanings. It is through gestures that the body speaks. In other words, gestures are closely related to speech, illustrating or supplementing it. Gestures are so common in daily life that attracts special attention of many experts. They are mostly concerned with speech and other ways of nonverbal communication, but sometimes they cannot stand alone. Generally speaking, a speaker uses gestures for two purposes: to reinforce an idea or to help describe something. Through gestures we can express our attitudes toward other.

A teacher may be considered as boring, stiff and inanimate, if he or she fails to use gestures while speaking. Comparatively, a lively and animated teaching style captures students' attention, and makes the material more interesting, facilitates learning and provides a bit of entertainment. In the process of the presentation, hand and arm movements are often employed to physically depict conceptual, intellectual, abstract, or narrative elements of the presentation. Using gestures in English classroom teaching can make some complex grammar points easier to understand.

4. Posture

People on earth all use posture to communicate. There are numerous body postures which offer insight into a culture's deep structure. An individual postures in a specific culture can send off a strong message. Scholars have found at least 10,000 significant different body attitudes capable of being maintained steadily.

For a teacher, standing or sitting in relaxing professional manner, is a positive posture, which can arouse students' positive attitude, and show that you are approachable, receptive and friendly. Being comfortably upright, squarely facing the students, and evenly distributing the weight are to change students' mood, draw students' attention, or reinforce some ideas. Traditionally, Chinese teachers, rated as Confucian scholars, are the souls of belief, knowledge and authority. Their image of power certainly ought not to be damaged by the unserious posture in Chinese traditional culture. However, nowadays, college students prefer college English teachers especially young teachers being casual and friendly.

5. Touch

For blind and deaf people, touch is the principle means of communication. Even the average person without these handicaps relies heavily on touch to communicate. We know that a slap on the back can mean a touch of friendship or a sign of encouragement and that stroking a dog or a cat conveys affection. Physical touch always communicates messages, especially emotional ones. Greetings and departures between friends and loved ones often involve touch in one way or another. Touch is also an efficient way of breaking down communication barriers. A full embrace, a kiss, a stroke of the face are ways of showing our love, and hand shaking can also easily make two strangers familiar to each other on their first meeting.

As the most extreme reduction of individual distance, touch is one of our most primitive and yet sensitive ways of relating to others, and plays a significant role in giving encouragement, expressing tenderness and showing emotional supports. It can be even more powerful than words sometimes, especially for establishing a link to students or conveying emotion. However, where these touches are directed is critical. Appropriate body contact means calmness, directness, belief and favor. The shoulder and arm are the most acceptable body areas to be touched, especially for the boys, and the chest and legs the least, especially for older girls. Back, head and hands are intermediate areas, but the head and hands, which are frequently touched by teachers of very young children, become less acceptable from ten or eleven onwards, especially for girls. As might be expected, all groups of students disliked angry types of touch, such as being hit or having their head twisted round. Furthermore, it is not common for college teachers to touch students. Most college students do not like teacher's touch, except for some necessary or particular situations such as encouraging touch combined with words, which would be more effective than verbal encouragement alone sometimes.

\section{B. Paralanguage}

Paralanguage is the way we vocalize or say the words we speak. The full and correct use of paralanguage in class is very powerful to the effective teaching and learning. Here we mainly deal with the use of ppp in college English classroom from two aspects: nonverbal sounds and pause and silence.

1. Nonverbal Sounds

The facet of nonverbal sounds, which is often named "vocal paralanguage", includes such vocal elements as intonation, tone, pitch, rhythm, volume, pace etc. These elements form a powerful, subtle and vital part of communication. Nonverbal sounds claim a person's emotional states. They also represent a person's demographic traits and indicate a person's personality characteristics.

As the disseminator of foreign language and the object whom the students try to imitate and learn from, English 
teachers should pay more attention to the aspects of nonverbal sounds. Effective English teachers are more likely to be good at varying their voice or convey different messages in different situations for different purposes. While presenting materials, effective English teachers are more inclined to employ emphatic intonation and few ungrammatical pauses, while the less important one is skimmed through quickly than the ineffective ones. As Sean expresses, teachers are more likely to use proclaiming tone when referring to aspects of their theme, which have already been covered once. Observations reveal that presentation with a loud voice, a high pitch and a fast rate is more likely to draw students' attention than that with a relatively quiet voice, a low pitch and a slow rate. Generally speaking, when there are key points in the process of teaching, or there exists some problems needing being emphasized, the teacher can raise his tone and slow down the speed. When in the process of statement, the mid-pitch and low-pitch can be alternatives, and the speed can be raised. When the students seem tired, the teacher should change his tone in time to make them excited again.

2. Pause and Silence

Pause, to some extend, is a kind of silence. It is a brief silence. Traditionally, silence has been defined as negatively as merely the absence of speech. However, silence is a rich conversational and expressive resource. Much of the time, brief silence or pauses and longer silence assume the function of contact or emphasis for spoken language. Although we accept the blank part of the page without notice, silences of any duration may draw our attention, and sometimes pauses or lengthy silences may become the foreground. Silence then becomes the medium for conveying a message.

In class, when a teacher gives a lecture, he may have brief pause or silence to achieve the purpose of contrast or emphasis for the presentation. Moreover, a teacher may pause a little when another topic is turned to. And a number of teachers may use silence as an effective means to dominate a noisy class. A student may keep silence, when he is uninformed or he is not clear about what a teacher says, or he is unwilling to answer a question. Sometimes, a student may be silent, when he agrees or disagrees with what has been said, or he is considering a question. In addition, the silence in language in teaching is also a very important aspect in terms of the language rhyme. There exists "The silence is gold." The change of the expression of language refers to the alternatives of humor and seriousness, which means that the ideal effect of teaching lies in the change of many kinds of style of language instead of being merely serious or humorous all the time. The feature of the students' recognition and attention is the proof of the change of teacher's language style.

\section{Spatial Language}

Space here refers to the distance between teachers and students. As we know, teaching and learning in classroom is a process of communication and the spatial distance between teachers and students is a "critical factor in the communication process". Whether the spatial distance between a teacher and his students in class is appropriate or not may affect positively or negatively on teaching and learning activities. In China, most students prefer their teachers moving around the classroom to the teacher's just standing at the very front between the blackboard and the platform. Some students think the teacher who walks around the room or stands closer to them is perceived as friendly and can make students more involved in class activities. On the other hand, it has also been found that teachers do stand further away from poor students or put them in the far end of the classroom. The teachers who conduct their classes while standing or walking among their students re viewed more positively than those standing at the front of the classroom, and are seen friendlier and are more effective than those who stand further away from the students.

According to our daily observation, when a student gets absent-minded or does something irrelevant to the teaching content, the teacher, if permitted, will move forward to the student if he or she does not want to interrupt the communication among the other students. Under this circumstance, the thing noticed is that the students bring back his attention and resumes his classroom activity. So here comes an indication that the closer the teacher is to the student, the better the student responds both in attitude and in academic performance. That is to say, there is a decrease in students' participation as the distance between teachers and students increases and as the directness with which they face each other decrease. If a teacher just stands behind the teacher's desk throughout the process of class, he neglects the fact that "motionless teachers can bore students".

\section{Time Language}

Time language is also called chronemics. It is the study of time, or more precisely, the study of how humans perceive, structure and use time as nonverbal communication.

In English class, time distribution can play a significant role. At the beginning of every class, the teacher can use five minutes to do a warming-up. The teacher can ask one student to make a short report about weather, news, or to tell a humor or just sing a song in English. This "warming-up" time can not only make each student have an opportunity to practice oral English, but also form an English atmosphere quickly. This is much better than start teaching as soon as class begins. During teaching process, "ask and answer" is a necessary chain. How much time for teachers to spend on a student is another aspect of the use of time. It is a rule that more difficult questions need more time to think, and less able students want more time to be cared about.

Another topic refers to time used in class is punctuality. Different cultures and different individuals have different attitudes toward what is punctuality, the appropriate times. Teachers in Chinese colleges are required to enter the classroom several minutes earlier for preparation before the class begins. It is also common that students are required to 
be on time for class. Those students who are punctual to class can impress teachers positively, while students who are frequently late for class may be perceived as irresponsible, lazy, or uninterested. Thus, we must be constantly aware of the messages we send through our use and misuse of time.

\section{CONCLUSION}

Nonverbal communication plays a significant role in our daily life and it has a credible and powerful influence on our daily classroom teaching. College English classroom teaching and learning, as a social interaction between teacher and students, is conducted by verbal means and nonverbal means. The effectiveness of teaching and learning in class, to some extent, depends on the proper use of nonverbal behaviors. As the college English teacher, we should hold that college English teaching aims to promote students' cross-cultural communicative competence which consists of verbal and nonverbal. Not only should college English teachers be equipped with knowledge of nonverbal communication, but also the students in colleges should be encouraged to improve their nonverbal communicative competence.

\section{REFERENCES}

[1] Bi Jiwan. (1995). Noverbal Communication In A Dictionary of British and American Culture edited by Hu Wenzhong. Beijing: Foreign Language Teaching and Research Press.

[2] Hu Wenzhong. (1994). Culture and Communication. Beijing: Foreign Language Teaching and Research Press.

[3] Hu Wenzhong. (1999). Intercultural Communication Series. Beijing: Foreign Language Teaching and Research Press.

[4] Jeremy, Hammer. (2000). How to Teach English: Foreign Language Teaching and Research. New York: Teachers College Press.

[5] Samovar. L \& Porter, R. (2000). Communication Between Cultures. Beijing: Foreign Language Teaching and Research Press.

[6] Xin Yue. (2003). The Use of Gesture Language. Beijing: China Textile \& Apparel Press.

[7] Zeng Puchu. (2005). English Teaching Environment Theory. Beijing: People's Education Press.

Liangguang Huang was born in Danyang, China in 1975. He received his B.A. degree in Foreign Linguistics and Applied Linguistics from Jiangsu University, China in 1997.

He is currently a lecturer in English Department, Zhenjiang Watercraft College of PLA, Zhenjiang, China. His research interests include Second Language Acquisition and Foreign Language Teaching. 